\title{
Improvement of Somatic Cervical Pain and Disability after the Application of a Portable TENS Device
}

\author{
Gabriela R. Lauretti*, Marcelo Antunes, Veridiana Marques Rebello Zuccolotto, Rogério Costa Franco \\ School of Medicine of Ribeirão Preto, University of São Paulo, São Paulo, Brazil \\ Email: *grlauret@fmrp.usp.br
}

How to cite this paper: Lauretti, G.R., Antunes, M., Zuccolotto, V.M.R. and Franco, R.C. (2016) Improvement of Somatic Cervical Pain and Disability after the Application of a Portable TENS Device. J. Biomedical Science and Engineering, 9, 451-459. http://dx.doi.org/10.4236/jbise.2016.910041

Received: August 3, 2016

Accepted: August 29, 2016

Published: September 1, 2016

Copyright $\odot 2016$ by authors and Scientific Research Publishing Inc. This work is licensed under the Creative Commons Attribution International License (CC BY 4.0).

http://creativecommons.org/licenses/by/4.0/

\section{Abstract}

Background: Cervical facet joints and neck muscles are common nociceptive pain generator, with neck and shoulder muscles pain, and limited retroflexion. Objective: To test the hypothesis that the portable TENS device would relieve cervical somatic pain. Methods: Forty-four patients with chronic cervical pain patients with somatic pain, but without radicular symptoms were evaluated in a double-blind, prospective, randomized fashion, divided into sham and active groups. The active TENS $\left(\mathrm{TANYX}^{\circledR}\right.$ ) or sham device was placed over C7-T1 spinous process, perpendicular to the spine, for $20 \mathrm{~min}$ at 12-hour interval during 3 days. The two groups were: placebo group (PG), with a sham device and the active TENS group (TG), which produced a mixed $(85 \mathrm{~Hz})$ frequency of stimulation, conventional, and burst. Diclofenac up to three times daily was available. Efficacy measures were pain relief, rescue analgesics and neck disability. Results: The active TENS device induced pain relief after its first application, which persisted during the 3-day treatment. By the end of the TENS application, the capability of rotation, lateral extension and retroflexion was improved $(p<0.05)$. The pain score and rescue analgesics consumption reduced in the TG $(p<$ $0.01, p<0.05$, respectively), and the mean pain score dropped from 8 to 3 points ( $p<$ $0.01)$. There were no adverse events. Conclusions: Somatic cervical pain and disability improved after active TENS application during the three consecutive days, which persisted upon the 1-month reevaluation.

\section{Keywords}

Cervical Somatic Pain, Neck Disability, TENS

\section{Introduction}

Cervical facet joints and neck muscles have been well ascertained in the literature as a 
customary nociceptive pain producer, with a projected prevalence that ranges from up to $66 \%$ of chronic axial neck pain [1]. The most ordinary symptom is pain without neuropathic characteristics, such as dermatomol referral; however movements linked with neck and shoulder muscles, such as neck retroflexion, are habitually painful or narrow [1] [2]. We tested the hypothesis that the new portable TENS device would relieve cervical pain, both facet and muscle pain, examples of nociceptive somatic pain.

\section{Methods}

The local Ethics Committee approved the study protocol, and informed consent was obtained from all patients. In this prospective, randomized, double-blinded, controlled study we studied 44 chronic cervical pain patients without radicular symptoms with insufficient pain relief (visual analogue scale (VAS) $>4$ ) treated with standardized analgesic therapy, with diagnosis of painful neck muscle combined with cervical facet pain. The same author, blind to the treatments interviewed the patients prior and after the TENS use.

Only patients complaining of pain on average $\geq 4 \mathrm{~cm}$ on a $10 \mathrm{~cm}$ pain VAS, taking no other drugs apart from analgesics such as metamizol, paracetamol or cyclobenzaprine, enrolled at the Center for Pain Treatment-Teaching Hospital were potentially qualified for inclusion. Diagnosis of nonappearance of radicular neuropathic and proof of nociceptive somatic pain was settled based on the clinical history and examination combined with cervical magnetic resonance to reject any pathologies. Patients were unqualified for the study if they had experienced surgery for radiculopathy within the last 3 months; if they had been once treated with TENS, suffered from dizziness, if they used non-steroidal anti-inflammatory drugs for the last 14-day prior to entrance into the study protocol, if they had agonized cervical pain for less than 3 months; if cervical pain was coupled with radiculopathy; if any surgery was anticipated within the next 6 months; if they had a pacemaker; if they were naive of non-pharmacological treatments including physiotherapy, acupuncture, mesotherapy, manipulations, wearing a corset, or psychological support; if their cervical was indicative of another condition (i.e., compression fractures or progressive inflammatory, neoplastic or infectious conditions); if the physician had appraised their life expectancy to be less than 3 months; and finally if articular, median branches, epidural or foraminal blocks were planned during the study period, or if the patient was involved in an ongoing medico-legal dispute.

All patients were previously thought about how to use the TENS device. The active TENS device (TG), produced a mixed sensory-level $85 \mathrm{~Hz}$ frequency of stimulation: 1) conventional (not pulsated, tonic), and 2) burst (intermittent clusters of frequent spikes). The frequency of $85 \mathrm{~Hz}$ was a constant of the device and could not be changed. The amplitude could be changed by the patient from 1) Zero-(turn off the device), 2) $\mathrm{L}-10 \mathrm{~mA}$, 3) $\mathrm{M}-20 \mathrm{~mA}$, and 4) $\mathrm{H}-30 \mathrm{~mA}$ (Figure 1). Either the portable and disposable $85 \mathrm{~Hz}$-frequency TENS device (TANYX ${ }^{\circledR} ; 15 \mathrm{~cm} \times 5 \mathrm{~cm}$ )), or sham device was placed centrally at the space between the $\mathrm{C} 7$ and $\mathrm{T} 1$ spinous processes, perpendicular to the spine, for $20 \mathrm{~min}$ at 12-hour interval during 3 days [3]. Patients were randomly 


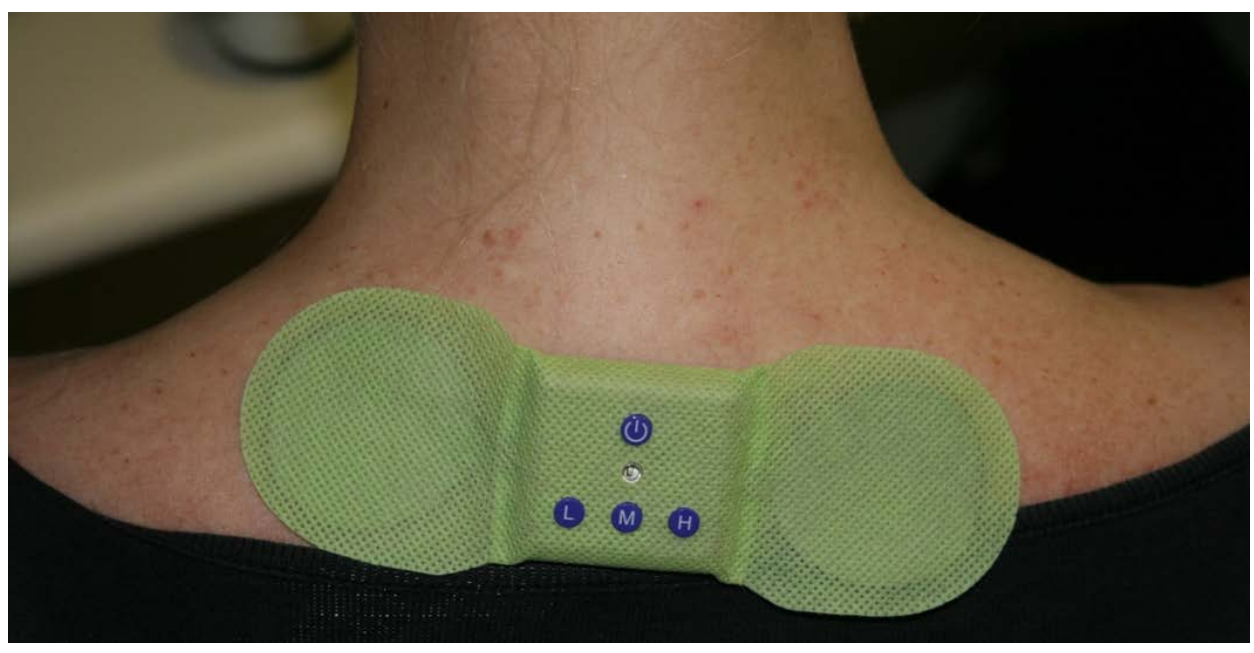

Figure 1. TENS cervical.

divided into two groups $(n=22)$. For the placebo group $(P G)$, the device did not transmitted electrical stimulus, although it was externally similar to the active one. The other patients applied the active TENS device (TG), which produced a conventional TENS characterized by continuous stimulation at high frequency $(85 \mathrm{~Hz})$, wave duration of $75 \mu$ s and intensity varying as $10 \mathrm{~mA}, 20 \mathrm{~mA}$ or $30 \mathrm{~mA}$, potentially achieving painless paresthesia only in the cervical region or tingling sensation. It was explained to patients not to obtain cervical muscle contraction, but only paresthesia feeling. Diclofenac (50 mg) up to three times daily was used as rescue analgesic if necessary for pain control. The efficacy measures were pain relief evaluated on: 1) a VAS scale, 2) reduction in use of rescue analgesics, 3) capability of rotation, lateral extension and retroflexion of the neck, and 4) capacity of performing routine physical activities, defined as maintained, improved, or worsened.

\section{Statistics}

The sample size of the study was based upon preliminary data conducted with 4 patients. It was hypothesized that the active TENS device would decrease cervical pain by $100 \%$ compared to the PG in the population studied. On this basis, with an alpha of $5 \%$, it was calculated that at least 18 evaluable patients would be needed to achieve an $80 \%$ power to detect any effect of TENS.

The normality of the distributions was assessed using the Shapiro-Wilk's test. Groups were compared for numerical data by Mann-Whitney-Wilcoxon test. Quantitative data were compared among groups by Chi-square and $p<0.05$ was considered significant.

\section{Results}

Patients were demographically similar related to age, American Society of Anesthesiology status (ASA), weight, height and gender ( $p>0.05$, Table 1$)$. One patient from the PG failed to complete data collection and was withdrawn from the final data evaluation.

The active TENS device induced gradually pain relief in 20 of 22 patients after its first 
Table 1. Demographic data.

\begin{tabular}{cccccc}
\hline & Age (years) & ASA I/II & Weight (kg) & Height (cm) & Gender (M/F) \\
\hline \multirow{2}{*}{ PG } & $42 \pm 6$ & $9(\mathrm{I})$ & $72 \pm 12$ & $172 \pm 6$ & $13(\mathrm{M})$ \\
& & $12(\mathrm{II})$ & & & $8(\mathrm{~F})$ \\
TG & $44 \pm 8$ & $14(\mathrm{I})$ & $78 \pm 9$ & $175 \pm 7$ & $12(\mathrm{M})$ \\
& & & & & $10(\mathrm{~F})$ \\
\hline
\end{tabular}

PG: placebo group; TG: TENS group; ASA: American Society of Anesthesiology $(p>0.05)$.

application, which persisted during the three-day treatment. Two patients from the TG turned the active TENS device on until obtaining cervical muscle contraction, instead of obtaining only paresthesia, and were more painful after the first day. The pain score was significantly reduced in the TG compared to the PG $(p<0.01)$, and the mean pain score dropped from 8 to 3 points $(p<0.01$, Table 2$)$ to the TG.

Concurrent use of analgesic tablets was also reduced $(p<0.05)$ in the TG compared to the PG and six patients stopped taking analgesics while using the active device ( $p<$ 0.05 , Table 2).

There were no differences between two groups in cervical activity in all directions before treatment $(p>0.05)$. By the end of the TENS application, the capability of rotation, lateral extension and retroflexion were worldly improved in the TG $(p<0.05)$. The capacity of performing routine physical activities during these three day-evaluation were defined as improved in 20 of 22 patients in the TG $(p<0.05$, Table 3$)$. In the PG, 19 of 21 patients referred maintenance of worsening of cervical disability and capacity of performing routine daily activities, while two patients the PG described as improved, although they maintained the daily rescue analgesic consumption $(p<0.05$, Table 3$)$.

Twenty TG participants subjectively found the device useful. There were no adverse events. On follow-up 1-month post-study, the twenty patients from the TG still referred improvement in neck pain and disability. Apart from local cervical muscle pain after inappropriate device application in the two patients from the TG, three patients observed itching sensation on the local of application. No other adverse effects were observed in any of the groups.

\section{Discussion}

A literature search regarding neck pain revealed inconsistent results and low quality evidence for cervical TENS up to date [4]. One of the reasons could be the lack of separation of the neuropathic and somatic type of pain, as it has been demonstrated that active TENS was effective only after somatic, but not neuropathic pain [5] [6]. Another reason could be the intensity of the neck pain. The TENS treatment was demonstrated to be effective for neck pain due to musculoskeletal disorders with subjects who have a mild neck pain rather than those with severe symptoms [7]. Recenty, cervical TENS was also demonstrated to improve pain intensity immediately in patients with myofascial chronic neck pain [8], nevertheless, electrotherapy of noxipoint at the trapezius and shoulder muscles was demonstrated to be more efficacious compared to TENS [9]. In this actual study we found that patients suffering from cervical articular facet and neck 
Table 2. Pain measurements.

\begin{tabular}{ccccc}
\hline & $\begin{array}{c}\text { Prior VAS } \\
(\mathrm{cm})^{*}\end{array}$ & $\begin{array}{c}\text { VAS after } \\
\text { TENS }\end{array}$ & $\begin{array}{c}\text { Prior } \mathbf{n}^{*} \text {. of } \\
\text { diclofenac tablets* }\end{array}$ & $\begin{array}{c}\mathbf{N}^{*} \text {. diclofenac } \\
\text { tablets after TENS* }\end{array}$ \\
\hline PG & $8(7-9)$ & $8(6-9)$ & $2(2-3)$ & $2(2-3)$ \\
TG & $8(7-9)$ & $3(2-4)$ & $2(2-3)$ & $1(0-2)$ \\
$p$ (between groups) & $p>0.05$ & $p<0.01$ & $p>0.05$ & $p<0.05$ \\
\hline
\end{tabular}

${ }^{\star}$ Data expressed as mean (25\% - 75\% percentile); VAS: visual analog scale.

Table 3. Neck disability and capacity of performing routine daily activities after 3-day TENS device.

\begin{tabular}{ccccc}
\hline & $\begin{array}{c}\text { Capability of } \\
\text { neck rotation }\end{array}$ & $\begin{array}{c}\text { Capability of neck } \\
\text { lateral extension }\end{array}$ & $\begin{array}{c}\text { Capability of } \\
\text { neck retroflexion }\end{array}$ & $\begin{array}{c}\text { Capacity of performing } \\
\text { routine activities }\end{array}$ \\
\hline \multirow{2}{*}{ PG } & 15 (maintained) & 14 (maintained) & 15 (maintained) & 15 (maintained) \\
& 4 (worsened) & 5 (worsened) & 4 (worsened) & 4 (worsened) \\
TG & 2 (improved) & 2 (improved) & 2 (improved) & 2 (improved) \\
& 20 (improved) & 20 (improved) & 20 (improved) & 20 (improved) \\
\hline
\end{tabular}

PG: placebo group; TG: TENS group; $p<0.05$ between groups.

muscle pain, that are examples of pure somatic type of pain, improved pain and disability after the active TENS daily application during the three consecutive days, which persisted at the one-month revaluation, combined to a lesser rescue daily analgesic consumption during the three-day evaluation, maintained up to one month evaluation. All patients from both groups reported a VAS pain qualified as $8-\mathrm{cm}$, which was considered strong, although not the strongest, probably in accordance to others [7].

Among the mechanisms involved, TENS efficacy appears to be mediated by the release of mu- or delta-opioids [3], and involve its ability to increase the vibration threshold probably due to distraction or antidromic block of large-diameter nerve fibres [10]. In addition, TENS analgesia appears to be caused mainly by differentially blocking the activation of large diameter primary afferents from deep somatic tissues, and not cutaneous afferents [11]. High frequency-TENS, as the device we used, was described capable of inducing analgesia, which was most likely related to increased serotonin release and also to block the adverse cardiovascular and respiratory changes induced by pain [12]. A superior mechanism of action was also identified through the periaqueductal gray that sends projections through the rostroventral medial medulla to the spinal cord to produce an opioid-mediated analgesia [13].

In the actual study, all patients used the TENS device for three-days, twice daily, during 20-min, where patients from the TG applied $85 \mathrm{~Hz}$ frequency, wave duration of $75 \mu \mathrm{s}$ and intensity of up to $30 \mathrm{~mA}$. Tolerance to the TENS have been suggested before, although with much higher currents with pulse duration (110 $\mu$ s), and pulse frequencies in healthy volunteers, during two consecutive days. However the authors found no ideal frequency versus time interaction and time-dependent for the outcome measures [14]. Other authors demonstrated that in rats, repeated administration of modulating 
frequency TENS lead to the development of opioid tolerance, which was delayed by approximately 5 days after low- or high-frequency TENS independently (3). Because we used the device for only three days with good results, we did not expect any tolerance effects development.

Recent trial revealed a better therapeutic effect obtained by combining traction with TENS in cervical spinal pain [15]. However neither neck manipulation, wearing neck collar, nor neck rehabilitation exercises were applied in the actual study during the one-month evaluation, in order to not interfere with the final results. Manipulation of miofascial trigger points were also not done as interactive neurostimulation therapy associated with myofascial trigger points in adults with mechanical neck pain was demonstrated effective [16] or at least similar when comparing manual therapy to TENS [17]. Interesting, both manipulation and mobilisation presented similar results for every outcome at immediate/short/intermediate-term follow-up after neck pain [18]. Again, no manual neck handling was included in the study protocol, in order to avoid bias.

Although the active TENS device was extremely effective in 20 of 22 patients, two patients applied the device with such an increased intensity that caused cervical muscles contraction and pain. Any TENS device is always supposed to be applied with enough intensity to obtain paresthesia only which recruits $\beta$-fibers [19]. When the amplitude is sufficient to $\mathrm{A} \alpha$-fibers recrutation [19] the resulting muscle contraction would act as pain generator. These patients continued the evaluation up to one month and complained of worse pain, although the device was correctly applied on the second and third days. Another interesting aspect is the itching sensation after TENS, observed by three patients in the TG, as described by others [20], although, controversially, TENS was also used to treat pruritus [21], with unfortunately unknown mechanisms.

Regarding the capability of: 1) neck rotation, 2) neck lateral extension, 3) neck retroflexion, and 4) capacity of performing routine physical activities, all patients who correctly applied the TENS device at C7-T1 improved, in accordance to others [4]. Few patients with cervical pain may complain of dizziness, what was not our case because of the exclusion criteria. TENS was found to influence cardiovascular responses by alleviating sympathetic activity [11] [22] to enhance visuospatial abilities and postural control [23], what would benefit patients. In our study, device was applied over C7-T1 dorsal spine, as the location of TENS electrodes is crucial for obtaining the strongest pain relief [22].

\section{Conclusion}

In conclusion, the TENS device induced gradually pain relief after its first application, which persisted during the three-day treatment and also decreased the concurrent use of analgesic tablets. Its use resulted in effective treatment alternative for nociceptive somatic cervical/neck pain, with no serious adverse effects when correctly applied, and because its characteristics of disposable and light, it could be used by the patient while doing their daily activities. 


\section{Acknowledgements}

The authors thank Medecell Brasil-Brazil for Tanyx and placebo donations. Other costs of the study were supported by the Center for Pain Management-HC-FMRP-USP. Teaching Hospital, School of Medicine of Ribeirão Preto, University of São Paulo, Brazil.

\section{References}

[1] Kirpalani, D. and Mitra, R. (2008) Cervical Facet Joint Dysfunction: A Review. Archives of Physical Medicine and Rehabilitation, 89, 770-774. http://dx.doi.org/10.1016/j.apmr.2007.11.028

[2] Jensen, I. and Harms-Ringdahl, K. (2007) Strategies for Prevention and Management of Musculoskeletal Conditions. Neck Pain. Best Practice \& Research Clinical Rheumatology, 21, 93-108. http://dx.doi.org/10.1016/j.berh.2006.10.003

[3] Desantana, J.M., Santana-Filho, V.J. and Sluka, K.A. (2008) Modulation between High- and Low-Frequency Transcutaneous Electric Nerve Stimulation Delays the Development of Analgesic Tolerance in Arthritic Rats. Archives of Physical Medicine and Rehabilitation, 89, 754-760. http://dx.doi.org/10.1016/j.apmr.2007.11.027

[4] Kroeling, P., Gross, A., Graham, N., Burnie, S.J., Szeto, G., Goldsmith, C.H., Haines, T. and Forget, M. (2013) Electrotherapy for Neck Pain. Cochrane Database of Systematic Reviews, 8, CD004251. http://dx.doi.org/10.1002/14651858.cd004251.pub5

[5] Lauretti, G.R., Chubaci, E.F. and Mattos, A.L. (2013) Efficacy of the Use of Two Simultaneously TENS Devices for Fibromyalgia Pain. Rheumatology International, 33, 2117-2122. http://dx.doi.org/10.1007/s00296-013-2699-y

[6] Buchmuller, A., Navez, M., Milletre-Bernardin, M., Pouplin, S., Presles, E., Lantéri-Minet, M., Tardy, B., Laurent, B. and Camdessanché, J.P., Lombotens Trial Group (2012) Value of TENS for Relief of Chronic Low Back Pain with or without Radicular Pain. European Journal of Pain, 16, 656-665. http://dx.doi.org/10.1002/j.1532-2149.2011.00061.x

[7] Maayah, M. and Al-Jarrah, M. (2010) Evaluation of Transcutaneous Electrical Nerve Stimulation as a Treatment of Neck Pain Due to Musculoskeletal Disorders. Journal of Clinical Medicine Research, 2, 127-136.

[8] León-Hernández, J.V., Martín-Pintado-Zugasti, A., Frutos, L.G., Alguacil-Diego, I.M., de la Llave-Rincón, A.I. and Fernandez-Carnero, J. (2016) Immediate and Short-Term Effects of the Combination of Dry Needling and Percutaneous TENS on Post-Needling Soreness in Patients with Chronic Myofascial Neck Pain. Brazilian Journal of Physical Therapy, in Press. http://dx.doi.org/10.1590/bjpt-rbf.2014.0176

[9] Koo, C.C., Lin, R.S., Wang, T.G., Tsauo, J.Y., Yang, P.C., Yen, C.T. and Biswal, S. (2015) Novel Noxipoint Therapy versus Conventional Physical Therapy for Chronic Neck and Shoulder Pain: Multicentre Randomised Controlled Trials. Scientific Reports, 5, 16342. http://dx.doi.org/10.1038/srep16342

[10] Palmer, S., Cramp, F., Propert, K. and Godfrey, H. (2009) Transcutaneous Electrical Nerve Stimulation and Transcutaneous Spinal Electroanalgesia: A Preliminary Efficacy and Mechanisms-Based Investigation. Physiotherapy, 95, 185-191.

http://dx.doi.org/10.1016/j.physio.2009.04.008

[11] Radhakrishnan, R. and Sluka, K.A. (2005) Deep Tissue Afferents, but Not Cutaneous Afferents, Mediate Transcutaneous Electrical Nerve Stimulation-Induced Antihyperalgesia. Journal of Pain, 6, 673-680. http://dx.doi.org/10.1016/j.jpain.2005.06.001 
[12] Santuzzi, C.H., Neto Hde, A., Pires, J.G., Gonçalves, W.L., Gouvea, S.A. and Abreu, G.R. (2013) High-Frequency Transcutaneous Electrical Nerve Stimulation Reduces Pain and Cardio-Respiratory Parameters in an Animal Model of Acute Pain: Participation of Peripheral Serotonin. Physiotherapy Theory and Practice, 29, 630-638. http://dx.doi.org/10.3109/09593985.2013.774451

[13] DeSantana, J.M., Da Silva, L.F., De Resende, M.A. and Sluka, K.A. (2009) Transcutaneous Electrical Nerve Stimulation at Both High and Low Frequencies Activates Ventrolateral Periaqueductal Grey to Decrease Mechanical Hyperalgesia in Arthritic Rats. Neuroscience, 163, 1233-1241. http://dx.doi.org/10.1016/j.neuroscience.2009.06.056

[14] Karakaya, I.C., Karakaya, M.G., Erğun, E., Elmalı, S. and Firat, T. (2014) Effects of Different Frequencies of Conventional Transcutaneous Electrical Nerve Stimulation on Pressure Pain Threshold and Tolerance. Journal of Back and Musculoskeletal Rehabilitation, 27, 197-201.

[15] Myśliwiec, A., Saulicz, E., Kuszewski, M., Wolny, T., Saulicz, M. and Knapik, A. (2012) The Effect of Saunders Traction and Transcutaneous Electrical Nerve Stimulation on the Cervical Spine Range of Motion in Patients Reporting Neck Pain-Pilot Study. Ortopedia Traumatologia Rehabilitacja, 14, 515-524. http://dx.doi.org/10.5604/15093492.1024714

[16] Schabrun, S.M., Cannan, A., Mullens, R., Dunphy, M., Pearson, T., Lau, C. and Chipchase, L.S. (2012) The Effect of Interactive Neurostimulation Therapy on Myofascial Trigger Points Associated with Mechanical Neck Pain: A Preliminary Randomized, Sham-Controlled Trial. Journal of Alternative and Complementary Medicine, 18, 946-952. http://dx.doi.org/10.1089/acm.2011.0142

[17] Escortell Mayor, E., Lebrijo Pérez, G., Pérez Martín, Y., Asúnsolo del Barco, A., Riesgo Fuertes, R., Saa Requejo, C. and TEMA-TENS Group (2008) Randomized Clinical Trial for Primary Care Patients with Neck Pain: Manual Therapy versus Electrical Stimulation. Atención Primaria, 40, 337-343. http://dx.doi.org/10.1157/13124126

[18] Gross, A., Langevin, P., Burnie, S.J., Bédard-Brochu, M.S., Empey, B., Dugas, E., Faber-Dobrescu, M., Andres, C., Graham, N., Goldsmith, C.H., Brønfort, G., Hoving, J.L. and LeBlanc, F. (2015) Manipulation and Mobilisation for Neck Pain Contrasted against an Inactive Control or Another Active Treatment. Cochrane Database of Systematic Reviews, 2015, Article ID: CD004249. http://dx.doi.org/10.1002/14651858.cd004249.pub4

[19] Yang, F., Chung, C.Y., Wacnik, P.W., Carteret, A.F., McKelvy, A.D., Meyer, R.A., Raja, S.N. and Guan, Y. (2011) Electrical Stimulation at Distinct Peripheral Sites in Spinal Nerve Injured Rats Leads to Different Afferent Activation Profiles. Neuroscience Letters, 505, 52-57. http://dx.doi.org/10.1016/j.neulet.2011.09.065

[20] Ozawa, M., Tsuchiyama, K., Gomi, R., Kurosaki, .F, Kawamoto, Y. and Aiba, S. (2006) Neuroselective Transcutaneous Electric Stimulation Reveals Body Area-Specific Differences in Itch Perception. Journal of the American Academy of Dermatology, 55, 996-1002. http://dx.doi.org/10.1016/j.jaad.2006.08.032

[21] Yüksek, J., Sezer, E., Aksu, M. and Erkokmaz, U. (2011) Transcutaneous Electrical Nerve Stimulation for Reduction of Pruritus in Macular Amyloidosis and Lichen Simplex. Journal of Dermatology, 38, 546-552. http://dx.doi.org/10.1111/j.1346-8138.2010.01081.x

[22] Chu, H., Li, M.H., Juan, S.H. and Chiou, W.Y. (2012) Effects of Transcutaneous Electrical Nerve Stimulation on Motion Sickness Induced by Rotary Chair: A Crossover Study. Journal of Alternative and Complementary Medicine, 18, 494-500. http://dx.doi.org/10.1089/acm.2011.0366

[23] Buonocore, M., Camuzzini, N., Cecini, M. and Dalla Toffola, E. (2013) High-Frequency 
Transcutaneous Peripheral Nerve Stimulation Induces a Higher Increase of Heat Pain Threshold in the Cutaneous Area of the Stimulated Nerve When Confronted to the Neighbouring Areas. Biomed Research International, 2013, Article ID: 464207.

http://dx.doi.org/10.1155/2013/464207

Submit or recommend next manuscript to SCIRP and we will provide best service for you:

Accepting pre-submission inquiries through Email, Facebook, LinkedIn, Twitter, etc. A wide selection of journals (inclusive of 9 subjects, more than 200 journals)

Providing 24-hour high-quality service

User-friendly online submission system

Fair and swift peer-review system

Efficient typesetting and proofreading procedure

Display of the result of downloads and visits, as well as the number of cited articles Maximum dissemination of your research work

Submit your manuscript at: http://papersubmission.scirp.org/ 